Research Paper

\title{
Chewing during prenatal stress prevents prenatal stress-induced suppression of neurogenesis, anxiety-like behavior and learning deficits in mouse offspring
}

\author{
Kin-ya Kubo1凶${ }^{\bowtie}$, Mika Kotachi², Ayumi Suzuki², Mitsuo Iinuma², Kagaku Azuma³ \\ 1. Graduate School of Human Life Science, Nagoya Women's University, 3-40 Shioji-cho, Mizuho-ku, Nagoya, Aichi, 467-8610, Japan \\ 2. Departments of 2 Pediatric Dentistry, Asahi University School of Dentistry, 1851 Hozumi, Mizuho, Gifu, 501-0296, Japan \\ 3. Department of Anatomy, School of Medicine, University of Occupational and Environmental Health, 1-1 Iseigaoka, Yahatanishi-ku, Kitakyusyu, 807-8555, \\ Japan \\ $\triangle$ Corresponding author: Kin-ya Kubo, PhD, Graduate School of Human Life Science, Nagoya Women's University, 3-40 Shioji-cho, Mizuho-ku, Nagoya, Aichi, \\ 467-8610, Japan. TEL/FAX: [+81] 52852 9442; E-mail: kubo@nagoya-wu.ac.jp \\ (c) Ivyspring International Publisher. This is an open access article distributed under the terms of the Creative Commons Attribution (CC BY-NC) license \\ (https://creativecommons.org/licenses/by-nc/4.0/). See http://ivyspring.com/terms for full terms and conditions.
}

Received: 2018.02.01; Accepted: 2018.04.30; Published: 2018.05.26

\begin{abstract}
Prenatal stress (PS) induces learning deficits and anxiety-like behavior in mouse pups by increasing corticosterone levels in the dam. We examined the effects of maternal chewing during PS on arginine vasopressin (AVP) mRNA expression in the dams and on neurogenesis, brain-derived neurotrophic factor (BDNF) mRNA expression, learning deficits and anxiety-like behavior in the offspring. Mice were divided into control, stress and stress/chewing groups. Pregnant mice were exposed to restraint stress beginning on day 12 of pregnancy and continuing until delivery. Mice in the stress/chewing group were given a wooden stick to chew during restraint stress. PS significantly increased AVP mRNA expression in the paraventricular nucleus (PVN) of the hypothalamus in the dams. PS also impaired learning ability, suppressed neurogenesis and BDNF mRNA expression in the hippocampus, and induced anxiety-like behavior in the offspring. Chewing during PS prevented the PS-induced increase in AVP mRNA expression of the PVN in the dams. Chewing during PS significantly attenuated the PS-induced learning deficits, anxiety-like behavior, and suppression of neurogenesis and BDNF mRNA expression in the hippocampus of the offspring. Chewing during PS prevented the increase in plasma corticosterone in the dam by inhibiting the hypothalamic-pituitary-adrenal axis activity, and attenuated the attenuated the PS-induced suppression of neurogenesis and BDNF expression in the hippocampus of the pups, thereby ameliorating the PS-induced learning deficits and anxiety-like behavior. Chewing during PS is an effective stress-coping method for the dam to prevent PS-induced deficits in learning ability and anxiety-like behavior in the offspring.
\end{abstract}

Key words: Chewing, Prenatal stress, Learning ability, Anxiety-like behavior, Neurogenesis, BDNF

\section{Introduction}

A growing body of evidence suggests that the prenatal period is a critical time for neurodevelopment and is thus a period of vulnerability for exerting long-term effects on brain development and behavior, which is closely related to physical and psychiatric health. Clinical studies indicate that a pregnant women's exposure to traumatic stress, as well as to chronic and common life stressors puts her offspring at risk for behavioral and emotional problems [1]. Developmental impairment of the brain due to prenatal stress (PS) is well established in rodents and is generally associated with anxiety, and depression-like behaviors, and cognitive deficits in the offspring throughout life [2-4]. PS leads to suppression of neurogenesis in the hippocampal dentate gyrus (DG) $[2,3,5]$, and decreased in brain-derived neurotrophic factor (BDNF) expression in the hippocampus [6] in the offspring.

Corticotropin-releasing hormone $(\mathrm{CRH})$ and arginine vasopressin (AVP) are considered important for mediating the hypothalamic-pituitary-adrenal (HPA) axis in response to stress [7]. Although acute stress markedly increases CRH mRNA expression, changes in AVP mRNA expression are less marked [8] 
in the paraventricular nucleus of the hypothalamus (PVN). In repeated or chronic stress conditions, CRH mRNA expression may increase, decrease, or remain unchanged [9-11]. After repeated stress, the CRH rapidly adapts [11]. AVP plays more important roles than CRH in sustaining HPA axis activity during repeated or chronic stress [7].

New neurons are produced throughout life in the subgranular zone of the hippocampal DG and the subventricular zone of the lateral ventricle [12]. Hippocampal neurogenesis comprises three biologic processes, cell proliferation, differentiation, and survival [13]. Approximately $80 \%$ of newborn cells move into the granule cell layer, mature into neurons $[14,15]$, extend axonal connections to CA3, and are functionally integrated into hippocampal neural circuitries [16], involved in hippocampal-mediated learning [17], anxiety, and emotional behavior [18, 19]. This neurogenesis is strongly influenced by various hormonal and environmental stimuli, such as stress or an enriched environment [20-22].

BDNF is a member of the neurotrophin family of growth factors, which are related to the canonical nerve growth factor, and is considered an important protein that influences brain function as well as the peripheral nervous system. BDNF regulates synaptic transmission, activity-dependent plasticity [23], and neurogenesis in the hippocampal DG [24, 25]. The clinical relationship between BDNF and mild cognitive impairment is understood [26], and BDNF is a potential biomarker for anxiety related to depression [27]. Stress-exposed animals exhibit reduced BDNF expression in the hippocampus, and depressed patients have decreased brain and blood levels of BDNF [28, 29].

Chewing is an effective stress-coping behavior [30-32]. In humans, gum chewing relieves stress and improves task performance, and in rodents chewing or biting under restraint or immobilization stress ameliorates stress-induced diseases such as gastric ulcer, and osteoporosis, and attenuates stress-induced cognitive and emotional impairment [30, 33-35]. Chewing under restraint stress rescues the increase in plasma corticosterone levels, deficits in spatial learning ability [36], and suppression of cell proliferation in the hippocampal DG [37]. Recently, we reported that chewing during PS ameliorates PS-induced learning deficits by decreasing plasma corticosterone levels in the dam [38]. The mechanism underlying the inhibitory effects of chewing during PS in the dam on PS-induced hippocampal behavioral and morphologic changes in the offspring has not yet been fully clarified. Here we examined the effects of chewing during PS on AVP expression in the dam, and on the survival/differentiation and proliferation of newborn cells in the hippocampal DG, BDNF mRNA expression in the hippocampus, and learning ability and anxiety-like behavior in the offspring.

\section{Materials and Methods}

\section{Animals}

DDY mice were purchased from Chubu Kagaku Shizai Co. Ltd. (Nagoya, Japan) and housed under standard laboratory conditions (12-h light/dark cycle, controlled temperature $\left(23 \pm 1^{\circ} \mathrm{C}\right)$ and humidity) with food and water available ad libitum. Pairs of male and female mice were matched overnight (the next day was designated gestational day 0 ), and then female mice were placed in individual cages and randomized to control $(C, n=8)$, stress $(S, n=8)$, or stress/chewing $(\mathrm{S} / \mathrm{C}, \mathrm{n}=8)$ groups. All experiments were performed according to the guidelines for the care and use of laboratory animals of Asahi University and Seijoh University. The ethics committee of Asahi University School of Dentistry and Seijoh University approved the study.

\section{Prenatal stress paradigm}

Pregnant females in the $\mathrm{S}$ and $\mathrm{S} / \mathrm{C}$ groups were individually restrained for $45 \mathrm{~min}, 3$ times a day during the light phase in plastic transparent cylinders (4.5 cm diameter, $10.3 \mathrm{~cm}$ long), in which they could move back and forth but not turn around, under bright light exposure from day 12 until delivery. Pregnant mice in the S/C group were allowed to chew on a wooden stick (diameter, $\sim 2 \mathrm{~mm}$ ) during the restraint period. Mice in the $C$ group were not restrained and remained in their home cages. After birth, the offspring were raised by their biologic mothers until weaning. At weaning, male pups were randomly selected from the $\mathrm{C}, \mathrm{S}$, and $\mathrm{S} / \mathrm{C}$ groups and assigned to the $\mathrm{CC}$, SC, and S/CC groups, respectively, and housed in groups of five under standard laboratory conditions.

\section{Hole-board test}

Mice were placed on the hole-board apparatus (400 mm x $400 \mathrm{~mm} \times 20 \mathrm{~mm}$, Model No. 6650, BrainScience Idea Co. Ltd, Osaka, Japan) with 16 holes ( $3 \mathrm{~cm}$ diameter) in a grid-pattern. An infrared beam sensor was installed on the wall to detect the number of head-dipping behaviors, and the latency to the first head-dips. Mouse behavior was recorded by an overhead color CCD camera linked to a computer system (Move-er/2D, Library Co., Ltd., Tokyo, Japan). One muse ( $n=5 /$ group) was placed on the floor of the hole-board and allowed 5 min to explore the board, and the time to the first head-dip, number of rearings and head-dips, and distance travelled were measured as described previously [39]. 


\section{Water maze test}

The Morris water maze test was performed as described previously [38, 40], using a stainless steel circular pool (diameter, $90 \mathrm{~cm}$; height, $30 \mathrm{~cm}$ ) filled to $23 \mathrm{~cm}$ with water $\left(\sim 23^{\circ} \mathrm{C}\right)$. One mouse ( $\mathrm{n}=5$ /group) was placed in the water from 1 of 4 randomly selected quadrants of the pool and allowed $90 \mathrm{~s}$ to locate a platform (12x12 cm, $1 \mathrm{~cm}$ under the surface) placed in the center of one of the quadrants, and given four acquisition trials per day for 7 days. Escape latency and swim path were recorded for each trial using a CCD camera linked to a computer system (Move-er/2D, Library Co., Ltd., Tokyo, Japan). All animals underwent a visible probe test $2 \mathrm{~h}$ after the last training trial on the last day of training.

\section{In situ hybridization analysis of AVP mRNA}

The mice (6/group) were anesthetized with pentobarbital sodium and perfused transcardially with $30 \mathrm{ml}$ of saline, followed by $100 \mathrm{ml}$ of $4 \%$ paraformaldehyde in $0.1 \mathrm{M}$ phosphate buffer, $\mathrm{pH}$ 7.4. The brains were removed and placed in $4 \%$ paraformaldehyde fixative overnight. The in situ hybridization method used in this study was described previously [41]. Briefly, $3-\mu \mathrm{m}$ thick sections were treated with $2 \mu \mathrm{g} / \mathrm{ml}$ proteinase $\mathrm{K}$ for $15 \mathrm{~min}$ at $37^{\circ} \mathrm{C}$. After post-fixation, the sections were treated with $0.2 \mathrm{~N} \mathrm{HCl}$, and acetylated with $0.25 \%$ acetic anhydride in $0.1 \mathrm{~mol} / 1$ triethanolamine $(\mathrm{pH} 8.0)$ for 10 min each. After treatment with $3 \%$ hydrogen peroxide for $1 \mathrm{~h}$, sections were dehydrated and air-dried. The hybridization mixture $(50 \mu \mathrm{l} ;$ mRNA In situ Hybridization Solution; Dako) with 50 ng cRNA probes [42] was loaded onto each section and hybridized for 16 to $18 \mathrm{~h}$ at $50^{\circ} \mathrm{C}$. After hybridization, the sections were immersed briefly in 5xSSC (1xSSC: $0.15 \mathrm{~mol} / 1 \mathrm{NaCl}$ and $0.015 \mathrm{~mol} / 1$ sodium citrate), and washed in $50 \%$ formamide/2xSSC for $30 \mathrm{~min}$ at $55^{\circ} \mathrm{C}$. The sections were then rinsed in TNE $(10 \mathrm{nmol} / 1$ Tris-HCl, $\mathrm{pH} 7.6 ; 1 \mathrm{nmol} / 1$ EDTA, $0.5 \mathrm{M} \mathrm{NaCl}$ ) for 10 min at $37^{\circ} \mathrm{C}$, and treated with $10 \mu \mathrm{g} / \mathrm{ml}$ RNase A (Roche Diagnostics) for $30 \mathrm{~min}$ at $37^{\circ} \mathrm{C}$. After rinsing again in TNE for $10 \mathrm{~min}$ at $37^{\circ} \mathrm{C}$, the sections were washed sequentially in $2 \mathrm{x}-\mathrm{SSC}, 0.2 \mathrm{xSSC}$, and $0.1 \mathrm{xSSC}$ for $20 \mathrm{~min}$ each at $55^{\circ} \mathrm{C}$. The sections were then rinsed in TBS(2)-T(0.01 mol/Tris-HCl, $\mathrm{pH} \mathrm{7.5;} 300 \mathrm{nmol} / \mathrm{l}$ $\mathrm{NaCl}, 0.5 \%$ Tween-20) three times for $5 \mathrm{~min}$ each, and in $0.5 \%$ casein/TBS $(0.01 \mathrm{~mol} / 1$ Tris- $\mathrm{HCl} \mathrm{pH} 7.5,150$ $\mathrm{nmol} / 1 \mathrm{NaCl}$ ) for $10 \mathrm{~min}$, and reacted with 1:400 diluted horseradish peroxidase-conjugated rabbit anti-DIG $\mathrm{F}\left(\mathrm{ab}^{\prime}\right)$ fragment antibody (Dako), 0.07 $\mu \mathrm{mol} / 1$ biotinylated tyramide solution, and 1:500 diluted horseradish peroxidase-conjugated streptavidin (Dako) for $15 \mathrm{~min}$ each at room temperature. Finally, the color was developed using the DAB Liquid System (Dako) and the sections were counterstained with Mayer's hematoxylin.

Hybridization with a $\beta$-2-microgloblin antisense strand probe was used as an internal control to confirm preservation of the mRNA. Hybridization with a CRH or AVP sense stand probe was used as a negative control.

AVP mRNA signals in the PVN (bregma: -0.70 $\mathrm{mm}$ to $-0.94 \mathrm{~mm}$ ) using the atlas of Franklin \& Paxinos [43] were quantitatively analyzed in all sections under a microscope with a $20 x$ objective, as described previously [44]. Image analysis was performed with Image J 1.32 software (W. Rasband, National Institutes of Health, zippy.nimh.nih.gov). The density of the AVP mRNA signals in the PVN was determined in a circular region $(0.21 \mathrm{~mm})$ with the highest density of CRH and AVP mRNA signals. The highest mean densitometric score in each hemisphere was determined by averaging four consecutive coronal sections. These same sections were used to evaluate the regional AVP mRNA density in the PVN. The highest mean density AVP mRNA scores obtained from each hemisphere were summed and averaged for each control and stressed animal. Similar paired comparisons were made to evaluate differences in the regional size of the AVP mRNA-expressing fields.

\section{Immunohistochemistry for neurogenesis}

For immunohistochemical analysis of cell proliferation, survival, and differentiation, 5-bromo-2'-deoxyuridine (BrdU; $50 \mathrm{mg} / \mathrm{kg} ; 10 \mathrm{mg} / \mathrm{ml}$ dissolved in $0.9 \% \mathrm{NaCl}$, Sigma-Aldrich, St. Louis, $\mathrm{MO})$ was intraperitoneally injected 5 times a day at 3-h intervals [45]. The next day (for proliferation, $\mathrm{n}=6$ /group) or 24 days (for survival, $\mathrm{n}=6$ / group) after BrdU injection, the mice were anesthetized with sodium pentobarbital, perfused transcardially with saline followed by $4 \%$ paraformaldehyde, and the brains were dissected out and placed in $4 \%$ paraformaldehyde at $4^{\circ} \mathrm{C}$ and cryoprotected in a $30 \%$ sucrose solution until sectioned.

The hippocampal sections ( $40 \mu \mathrm{m}$ thick) were prepared on a cryostat (CM1850, LEICA, Wetzlar, Germany). For DNA denaturing, the sections were incubated at $65^{\circ} \mathrm{C}$ for $2 \mathrm{~h}$ in $50 \%$ formamide/ $2 \mathrm{x}$ saline sodium citrate $(0.3 \mathrm{M}$ sodium chloride and $0.03 \mathrm{M}$ sodium citrate), incubated for $30 \mathrm{~min}$ in $2 \mathrm{~N} \mathrm{HCl}$ at $37^{\circ} \mathrm{C}$, and neutralized for $10 \mathrm{~min}$ in $0.05 \mathrm{M}$ Tris-buffered saline (TBS, $\mathrm{pH}$ 8.5). The sections were rinsed with phosphate-buffered saline (PBS, pH7.4), incubated with $1 \% \mathrm{H}_{2} \mathrm{O}_{2}$ for $10 \mathrm{~min}$, rinsed with PBS, and incubated for 60 min with 5\% normal goat serum using the $A B C$ method. The sections were rinsed again with PBS and incubated with rabbit polyclonal 
anti-BrdU antiserum (Abcam PLC, Cambridge, UK) diluted 1:200 in PBS containing 0.3\% Triton X-100 at $4^{\circ} \mathrm{C}$ for $48 \mathrm{~h}$, rinsed with PBS, and then incubated with biotinylated goat anti-rabbit IgG (Dako Cytomation, Glostrup, Denmark) diluted 1:500 in PBS for $2 \mathrm{~h}$. After rinsing with PBS followed by $0.05 \mathrm{M}$ Tris- $\mathrm{HCl}$ buffer ( $\mathrm{pH}$ 7.6), sections were incubated with peroxidaseconjugated streptavidin (Dako Cytomation) diluted 1:500 with TBS for $1 \mathrm{~h}$. Visualization of the bound complex was achieved using 3,3'-diaminobenzidine $(0.5 \mathrm{mg} / \mathrm{ml})$ and hydrogen peroxidase $(0.01 \%)$ in TBS.

To evaluate newborn cell differentiation, the mice ( $n=6 /$ group) were perfused 21 days after the BrdU injections, and double immunofluorescence staining was performed to determine the colocalization of BrdU with neuronal nuclei (NeuN) or glial fibrillary acidic protein (GFAP), as previously described [13]. After denaturing the DNA as described above, sections were incubated with a sheep polyclonal anti-BrdU antibody (1/200; Abcam) and rabbit polyclonal anti-GFAP antibody (1/1000; Millipore, Billerica, MA) or with mouse monoclonal anti-NeuN antibody [1/100; Millipore]. Bound anti-BrdU was visualized with donkey anti-sheep IgG, fluorescein isothiocyanate (FITC) conjugate (1/100; Santa Cruz Biotechnology, Dallas, TX); anti-GFAP was visualized using donkey anti-rabbit JgG FITC conjugate $[1 / 100 ;$ Santa Cruz Biotechnology], and anti-NeuN antibodies were visualized using donkey anti-mouse IgG FITC conjugate (1/100; Santa Cruz Biotechnology).

\section{Quantification of BrdU-positive cells and phenotype of newborn cells}

To quantify BrdU-positive cells in the hippocampal DG, every 6th section (120- $\mu \mathrm{m}$ apart) of the series was selected and 8 sections for each mouse were quantified (bregma $-2.12 \mathrm{~mm}$ to $-6.30 \mathrm{~mm}$ ) [43] using an unbiased stereologic method under a microscope with $4 x$ objective (Olympus BX-50, Japan) as previously described [46]. At least $50 \mathrm{BrdU}$-labeled cells were measured in each brain, and the number of double-labeled cells was expressed relative to the total number of BrdU-positive cells [13].

\section{Real-time PCR for BDNF mRNA expression}

After decapitation under anesthesia, the mouse hippocampus (6/group) was removed from the brains and pooled. Hippocampi were stored in either TRIzol RNA Isolation Reagents (Invitrogen, Carlsbad, USA) for determination of $B d n f$ mRNA expression and stored at $-80^{\circ} \mathrm{C}$ for determination of $B d n f$ expression. Real-time PCR was performed on ABI PRISM ${ }^{\circledR} 7500$ Real Time PCR system (Applied

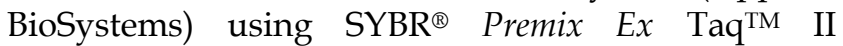

(TaKaRa). The mRNA expression levels were normalized using glyceraldehyde 3-phosphate dehydrogenase (Gapdh). RNA isolation and reverse transcription- polymerase chain reaction were performed as described previously [47]. Mouse cDNA synthesis was performed the using PrimeScript ${ }^{\mathrm{TM}}$ RT Reagent Kit (TaKaRa) according to the manufacturer's protocol. The primer sequences for Bdnf and Gapdh are listed in Table 1. Each sample $[\mathrm{n}=6]$ was run in duplicate and repeated three times. To normalize mRNA expression, housekeeping genes (Gapdh) were selected as the internal control.

\section{Statistical analysis}

All data are represented as mean $\pm \mathrm{SE}$. Analysis of variance or factorial analysis of variance were used to analyze the data, followed by Tukey's post hoc multiple comparison tests to evaluate the statistical significance of the behavioral or morphologic differences between groups. A P value of less than 0.05 was considered significant.

Table 1. Primer used for real-time PCR analysis

\begin{tabular}{lll}
\hline mRNA & $\begin{array}{l}\text { Size } \\
(\mathrm{bp})\end{array}$ & primer sequence \\
\hline BDNF & 121 & $\begin{array}{l}\text { Forward 5'-TCAAGTTGGAAGCCTGAATGAATG-3' } \\
\text { Reverse 5'-CTGATGCTCAGGAACCCAGGA-3' }\end{array}$ \\
GAPDH & 137 & $\begin{array}{l}\text { Forward 5'-TGTTCCTACCCCCAATGTT-3' } \\
\text { Reverse 5'-GGTCCTCAGTGTAGCCCAAG-3' }\end{array}$ \\
\hline
\end{tabular}

\section{Results}

\section{AVP mRNA expression}

Typical photomicrographs of AVP mRNA signals in the PVN and the incidence of AVP mRNA signals are shown in Figure 1A and 1B. AVP mRNA expression in the PVN differed significantly between the $C$, S, and S/C mice $[F(2,29)=49.9575, P<0.01]$. AVP mRNA expression in the $S$ group was $296 \%(P<0.01)$ and $267 \%(P<0.01)$ higher than that in the $C$ and $S / C$ groups, respectively. No significant difference in AVP mRNA expression was detected between the $C$ and S/C groups.

\section{Hole-board performance}

Rearing counts differed among the three groups $[F(2,14)=18.483, P<0.01]$. Rearing counts were larger in the SC group than those in CC $(P<0.01)$ and $\mathrm{S} / \mathrm{CC}(P<0.05)$ groups. No significant difference in rearing counts was detected between the $\mathrm{CC}$ and S/CC groups (Fig. 2A).

Distance travelled differed among the three groups $[F(2,14)=100.4905, P<0.01]$. Distance travelled was longer in the SC group than that in the CC $(P<0.01)$ and $\mathrm{S} / \mathrm{CC}(P<0.01)$ groups. No significant 
difference in distance travelled was detected between the CC and S/CC groups (Fig. 2B).

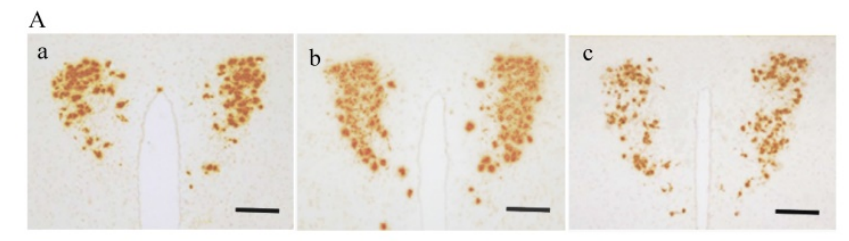

B

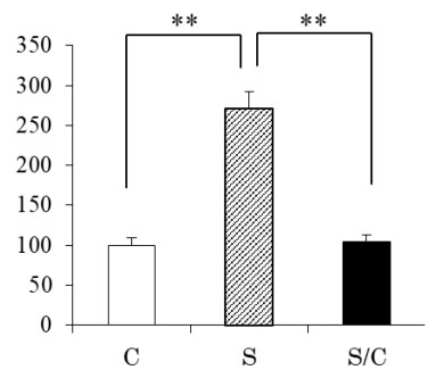

Figure 1. Photomicrographs showing vasopressin mRNA signals in the PVN (1A), the effect of chewing during PS on AVP mRNA expression in the PVN (1B). Mean [ \pm SE] AVP expression in C, S, S/C groups [n=6/group]. The graph shows the change relative to the $C$ group, with the $C$ group used as a base of 100\% (1B). Bars: $100 \mu \mathrm{m}$, **: $P<0.01$. Note the increase in AVP mRNA expression in the $S$ group compared to the $C$ and $S / C$ groups.
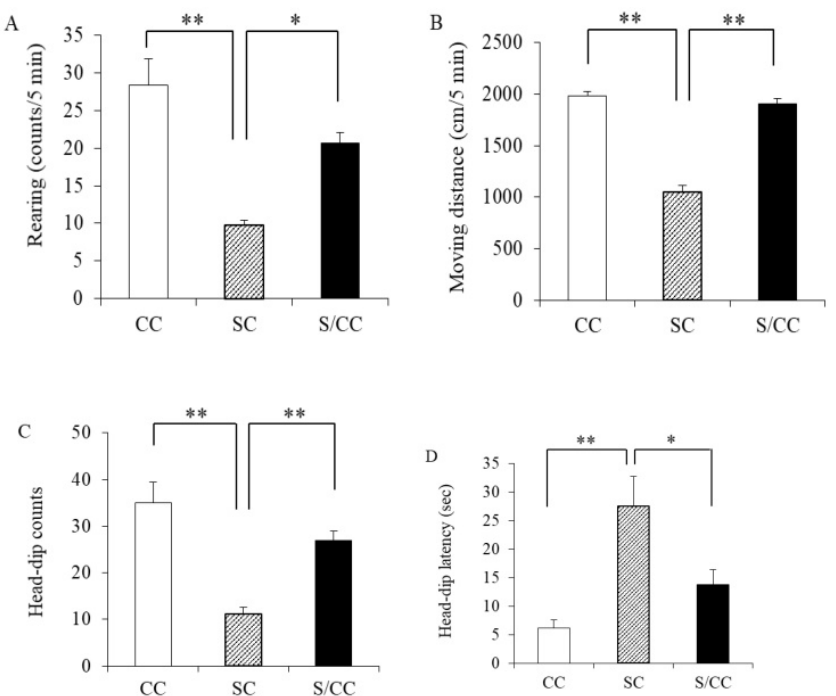

Figure 2. Effects of chewing during PS on the hole-board test performance, i.e., Rearing (2A), Distance travelled (2B), Head-dip counts (2C), and Head-dip latency (2D). The results are expressed the mean count or time [mean $\pm S E, n=5$ for each group]. ${ }^{* *}: P<0.01, *: P<0.05$. Note the greater reduction in the rearing, moving distance, head-dip counts, head-dip latency in the $S$ group.

The number of head-dips differed significantly between groups $[F(2,14)=17.0294, P<0.01]$ (Fig. 2C). The number of head-dips was lower in the SC group than that in the CC $(P<0.01)$ and S/CC $(P<0.01)$ groups, but there were no significant difference in the time to the first-head-dip between the CC and S/CC groups Fig. 2C).

Time to the first head-dips differed significantly among the three groups $[F(2,14)=10.0193, P<0.05]$ (Fig. 2D). Time to the first head-dips was longer in the SC group than in the CC $(P<0.01)$ and S/CC $(P<0.05)$ group, but no significant difference in the time to first head-dips was detected between CC and S/CC groups (Fig. 2D).

\section{Water maze performance}

Water maze performance improved in all mice during acquisition, as indicated by the reduced mean escape latency over the 7 training days $[F(6$, $72)=32.063, P<0.01]$ (Fig. 4). The escape latencies of the mice differed significantly among the three groups $[F(2,12)=17.029, \quad P<0.01]$. Escape latencies were significantly longer in the SC group than in the CC and S/CC groups, but no significant difference was detected between the CC and S/CC groups. Performance in the visible probe test did not differ significantly among groups.

\section{Neurogenesis}

\section{Cell proliferation in the hippocampal DG}

The number of proliferating cells differed significantly among the three groups $(F(2$, 17) $=1935.428, P<0.01]$ (Fig. 4A). The SC group had significantly fewer BrdU positive cells than the CC $(P<0.01)$ and $S / C C(P<0.01)$ groups, but no significant difference in the number of BrdU-positive cells was detected between the S/CC and CC groups.

\section{Newborn survival in the hippocampal DG}

The number of surviving cells differed significantly among the three groups $[F(2$, 17)=16.8992, $\quad P<0.01$ ] (Fig. 4B). The number of surviving cells was lower in the SC group than in the mice CC $(P<0.01)$ and S/CC $(P<0.01)$ groups, but no significant difference in the survival of newborn cells was detected between the CC and S/CC groups.

\section{Newborn cell differentiation in the hippocampal DG}

The phenotype of mature BrdU-positive cells was determined based on BrdU double-labeling with either NeuN or GFAP (Fig. 5A). The majority of BrdU-positive cells were immunoreactive for NeuN in the CC (79.1\%), SC (60.3\%), and S/CC (76.2\%) groups. The amount of NeuN immunoreactivity was significantly different between the three groups $[F(2$, $18)=13.1093, \quad P<0.01]$. The amount of NeuN immunoreactivity was significantly lower in the SC group, than in the CC $(P<0.01)$ and S/CC $(P<0.01)$ groups. No significant difference in the amount of NeuN was detected between the CC and S/CC groups. The number of BrdU-positive cells immunoreactive for GFAP did not differ significantly among the three groups (CC, $18.1 \%$; SC, $16.5 \%$; S/CC, $18.0 \%)[F(2,17)=0.3748, P=0.69]$. These results suggest that chewing during PS increases cell differentiation into neurons. 


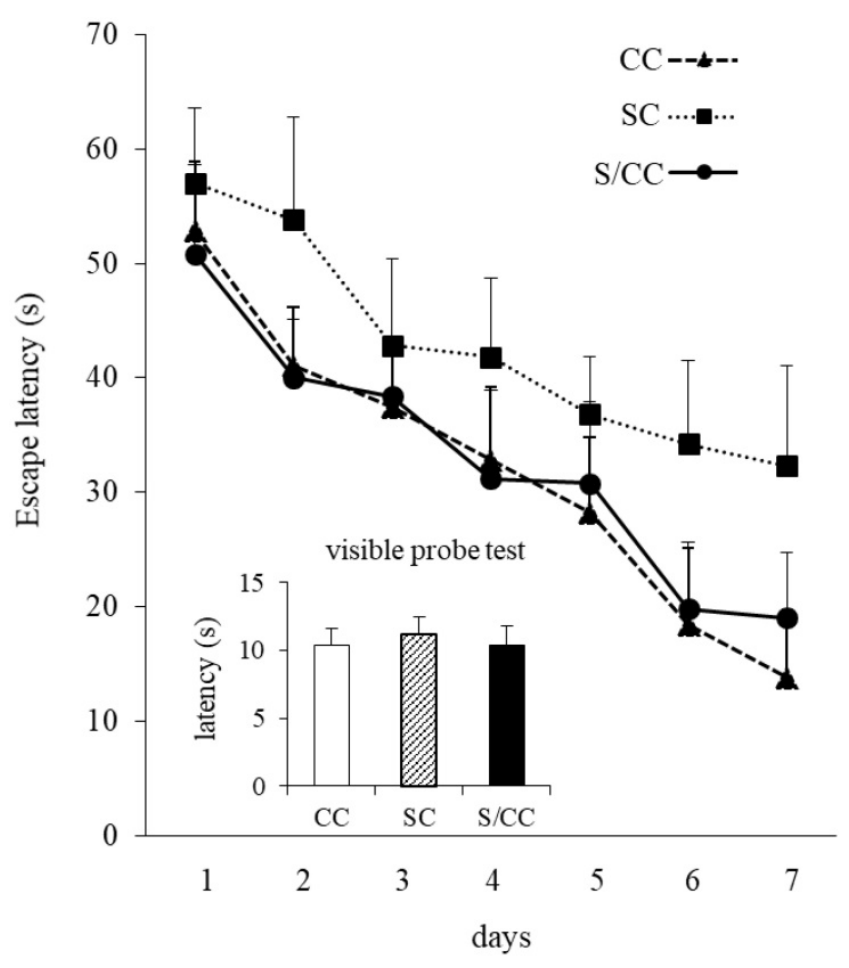

Figure 3. Spatial learning in the Morris water maze test. The results are expressed as the mean score [mean $\pm S E, n=5 /$ group] of four trials per day. Note that the $S$ group required a longer time to reach the platform.

\section{Hippocampal BDNF mRNA expression}

BDNF mRNA expression in the hippocampus of the three groups is shown in Fig. 4A significant difference was detected in BDNF mRNA expression among the three groups $[F(2,17)=16.604, P<0.01]$. The hippocampal BDNF mRNA expression was decreased in the SC group by $32.1 \%(P<0.01)$ and $28.9 \%(P<0.01)$ compared with $C C$ and S/CC groups, respectively. The hippocampal BDNF mRNA expression did not differ significantly between CC and S/CC groups.

\section{Discussion}

In the present study, we found that chewing during PS prevented not only stress-induced AVP expression in the PVN in the dam, but also ameliorated the PS-induced suppression of proliferation, survival, and differentiation of newborn cells in the hippocampal DG, and the decrease in BDNF mRNA expression in the hippocampus in the offspring. In offspring whose dams were allowed to chew on wooden sticks during restraint stress, PS-induced anxiety-like behavior and learning deficits were also attenuated. The morphologic and behavioral changes in dams in this study were consistent with the changes in plasma corticosterone levels in our previous reports $[38,40]$.

\section{A}
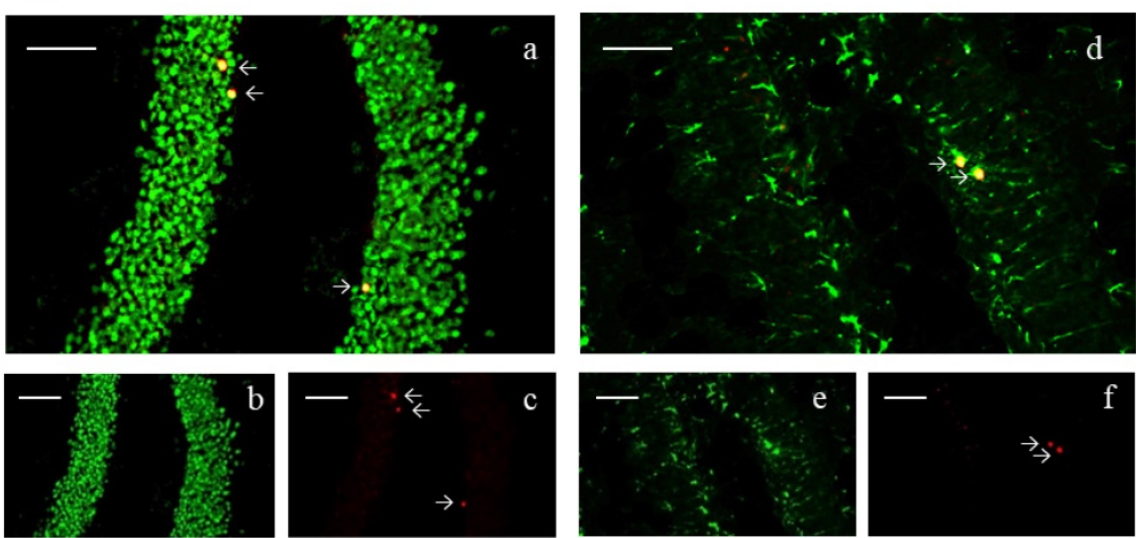

$\mathrm{B}$

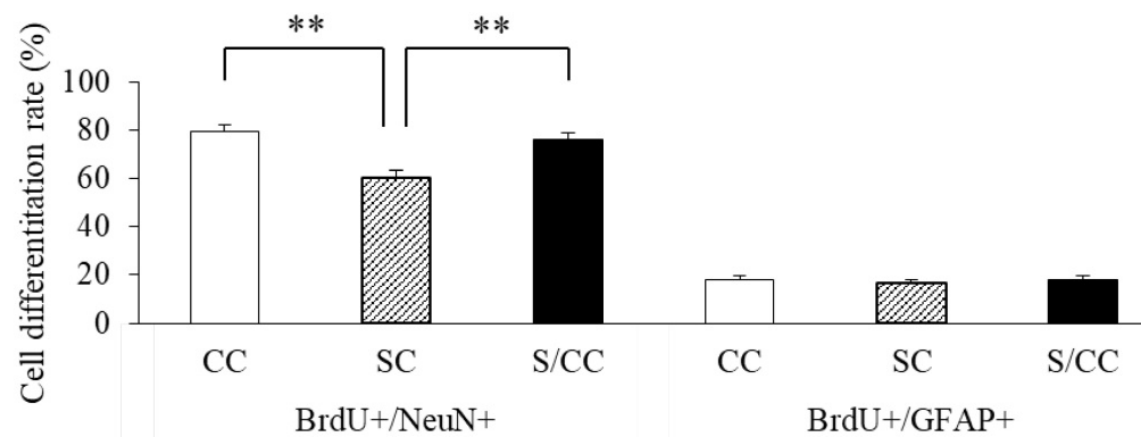

Figure 4. Representative dual immunofluorescence micrographs of BrdU and NeuN (a-c) or GFAP (d-f) in the hippocampal DG (4A). Colocation of BrdU (red, b and e) and NeuN (green, c) or GFAP (green, $f$ ) and the merged image (a and d). Bars: $100 \mu \mathrm{m}$. The percentage of newly generated cells [mean \pm SE, $n=6$ for each group] (4B). The percentage of BrdU+/NeuN+ cells was significantly decreased in the SC group. The percentage of BrdU+/GFAP+ cells did not differ significantly among the three groups. 

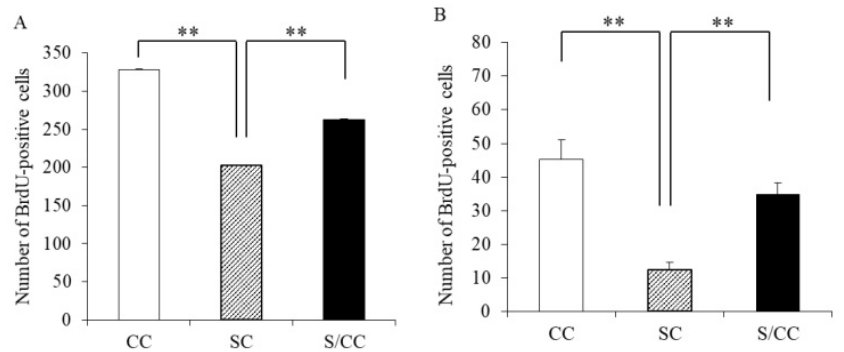

Figure 5. Effects of chewing during PS on cell proliferation (5A) and survival (5B) of newborn cells in the DG of hippocampus. The results are expressed the mean number of BrdU-positive cells [mean $\pm \mathrm{SE}, \mathrm{n}=6$ for each group]. $* *$ : $P<0.01$. Note the greater reduction in cell proliferation and survival of newborn cells in the DG in the SC group.

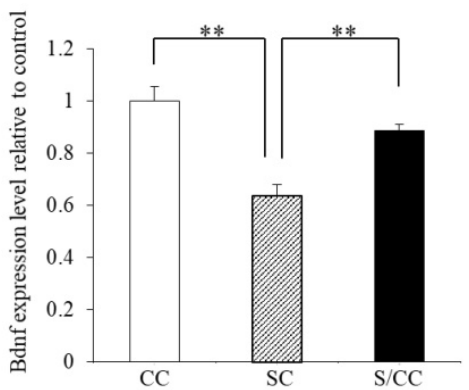

Figure 6. Effects of chewing during PS on quantitative PCR BDNF expression levels. Mean $[ \pm S E]$ BDNF mRNA expression in the $C, S, S / C$ groups [ $n=6 /$ group]. The graph shows the change relative to the $C$ group, with the $C$ group used as a base of $100 \%$. **: $P<0.01$. Note the decrease in BDNF mRNA expression in the $\mathrm{S}$ group compared with the $\mathrm{C}$ and $\mathrm{S} / \mathrm{C}$ groups.

Maternal exposure to various types of stress during pregnancy impairs brain development in the offspring, resulting in wide-ranging and long-lasting effects on their brain function and behavior. Some types of psychiatric and behavioral disorders in humans have developmental origins [48, 49], and prenatal stress in rodents dramatically induces anxiety- and depressive-like behavior in offspring throughout the lifetime [50,51]. Glucocorticoid is a key mediator regulating prenatal stress and dysfunction of the negative feedback control of the HPA axis by glucocorticoid exposure during pregnancy in the offspring increases the risk for developing psychiatric disorders and cognitive deficits $[52,53]$. The response of the HPA axis to novel stress is enhanced in prenatally stressed offspring, which increases their vulnerability to neuropsychiatric disorders [54]. The stress-induced vulnerability is supported by findings of a stress-induced reduction of hippocampal mineralocorticoid and glucocorticoid receptor mRNA expression [55]. The elevated plasma corticosterone levels and AVP expression observed in this study are very similar to findings of previous studies in which plasma corticosterone levels and AVP expression in the PVN were increased under chronic stress conditions [38, 56, 57]. CRH and AVP are secreted from parvocellular neurons of the PVN and control the plasma corticosterone levels via the HPA axis in response to internal or external environmental changes, including stress. Both CRH and AVP mRNA expression levels are increased in acute stress conditions [52]. The response of $\mathrm{CRH}$ mRNA to repeated or chronic stress, however, is much more complex. Depending on the stress paradigm, the expression of CRH mRNA levels in the hippocampus may increase, decrease, or remain unchanged $[9,10$, 58]. The response of AVP plays a much more prominent role in regulating HPA axis activity during repeated or chronic stress compared with the $\mathrm{CRH}$ response [9, 59]. Stress-induced increases in the plasma corticosterone levels and phosphorylation of extraventricular signal-related protein kinase $1 / 2$ [pERK1/2] induction and CRH expression in the PVN is attenuated by chewing during repeated restraint and acute immobilization stress [37, 60 61]. The stress-induced decrease in glucocorticoid receptor expression in the hippocampal CA1 region is attenuated by chewing during the immobilization stress [62]. In addition, providing the dams with wooden sticks to chew during prenatal stress inhibits the stress-induced increase in plasma corticosterone levels in the dam [38]. In the present study, restraint stress increased plasma corticosterone levels and AVP mRNA expression, and chewing during restraint stress attenuated the increase in the plasma corticosterone levels and AVP mRNA expression in the PVN in the dams. These findings suggest that restraint stress acts as a chronic stressor and chewing during prenatal stress ameliorates the stress response in the dams, thereby attenuating the stress-induced leading deficits and anxiety-like behavior in the offspring.

The hippocampus has a low tolerance for stress. Neurogenesis occurs in the hippocampus throughout adulthood and these newborn neurons are integrated into the hippocampal neuronal circuitry and contribute to hippocampal function [63]. Hippocampal neurogenesis regulates various cognitive processes such as learning and memory, as well as anxiety and emotional behavior [18, 19, 63, 64]. Hippocampal neurogenesis is influenced by various internal and external environmental changes. Excessive glucocorticoids reduce neurogenesis in the hippocampus [20] and an enriched environment such as voluntary wheel running enhances hippocampal neurogenesis [21, 22]. BDNF is a secreted protein that regulates neuronal development and function, and is predominantly expressed in the hippocampus, cerebral cortex, and amygdala [65]. BDNF controls neuronal plasticity and is implicated in neurogenesis in the hippocampal DG, learning ability, and anxiety 
disorders [24, 25]. Prenatal stress in animals leads to increased anxiety- and depressive-like behavior, and learning deficits [5, 3], and suppression of hippocampal DG neurogenesis in offspring $[3,66]$. Prenatal stress perturbs BDNF biosynthesis in the hippocampus of the offspring, but the precise effects are not clear. Some studies report a reduction in hippocampal BDNF protein, while others indicate that BDNF protein levels in the hippocampus are increased in PS offspring $[67,68]$. In the present study, we found that PS suppressed BDNF mRNA expression in the offspring hippocampus, induced learning impairments and anxiety-like behavior. These discrepancies may be due to differences in the age of the offspring and the experimental methods used such as the type of stress. Chewing during PS increased BDNF mRNA expression in the hippocampus, and suppressed PS-induced learning deficits and anxiety-like behavior, and neurogenesis in the hippocampal DG in the offspring. Therefore, allowing the dams to chew on a wooden stick during PS may protect against PS-induced deficits in learning ability and anxiety-like behavior by attenuating the effects of stress on neurogenesis and BDNF mRNA expression in the hippocampus of the offspring.

The medial prefrontal cortex (mPFC) and amygdala are directly connected. Both structures are involved in regulating stress-related responses and modulating hippocampal function, such as learning and memory, and psychiatric behavior $[69,70]$. The locus coeruleus contains the largest groups of noradrenergic neurons in the central nervous system, and plays a role in promoting behavioral adaptation to stress [71]. The locus coeruleus innervates the cerebral cortex of both hemispheric lobes and limbic areas, including the prefrontal cortex and amygdala, and is involved in neuroendocrine function by projecting neuroendocrine cells to the PVN [72, 73]. Noradrenergic and dopaminergic neuronal systems are modulated by various types of stress and contribute to the pathogenesis of anxiety and cognitive deficits [74, 75]. Restraint stress activates noradrenergic neurons in the locus coeruleus [76], novelty exposure induces the preferential activation of the prefrontal cortical dopaminergic system [77], and tail pinch stress increases striatal dopaminergic activity [78]. On the other hand, some reports indicate that chewing under stressful conditions suppresses the stress-induced changes in various areas of the central nervous system. Chewing under immobilizeation stress prevents a stress-induced increase in phosphorylated extracellular signal-related kinase in the periaqueductal gray with major cortical inputs from areas involved in emotional regulation, such as the $\mathrm{MPFC}$ and amygdala [79]. Chewing in response to brief restraint stress attenuates the stress-induced reduction of gamma-aminobutyric acid-stimulated chloride uptake in the frontal cortex and amygdala after the stress exposure [80]. Rats allowed to chew on a wooden stick while being exposed to restraint stress exhibited a suppressed stress-induced noradrenaline release in the amygdala [33]. Dopamine activity in the right prefrontal cortex is modulated by coping processes and plays a critical role in stress-related actions in the prefrontal cortex [81]. In addition, tail pinch stress increases striatal dopamine activity in rats, while non-functional masticatory activity during the stress attenuates the increase in striatal dopaminergic neurotransmission induced by the stressor [78]. By measuring the brain levels of 3,4-dihydroxyphenylacetic acid, the major catabolite of dopamine, Berridge et al. found that chewing attenuates stress-induced dopaminergic utilization in the frontal cortex [77]. Chewing during exposure to novelty stress induces an increase in Fos immunoreactivity in the right hemisphere of the $\mathrm{mPFC}$, and a decrease in Fos-immunoreactivity in the right central nucleus of the amygdala, suggesting that coping by chewing under stressful conditions engages the neuronal activity of the $\mathrm{mPFC}$ and amygdala asymmetrically [81]. Chewing during restraint stress increases dopaminergic activity in the hippocampus, which suppresses stress-induced anxiety-like behavior and long-term potentiation in the hippocampus [82]. Together these findings suggest that neural mechanisms of coping with stress by chewing may be modulated by catecholaminergicmediated suppression of the stress-induced activation of the mPFC and amygdala. Further studies are needed to clarify the neural mechanism of coping stress by chewing or biting during PS.

The findings of the present study indicate that maternal chewing during PS effectively ameliorates stress-induced increases in plasma corticosterone levels in the dam decreasing AVP expression in the PVN, and, in the adult offspring, prevents PS-induced learning deficits, anxiety-like behavior, and impaired neurogenesis due to the suppression of BDNF mRNA expression in the hippocampus.

\section{Acknowledgments}

This work supported in part by a Grant-in-Aid for Scientific Research (B) and Challenging Exploratory Research from the Ministry of Education, Culture, Sports, Science, and Technology of Japan (KAKENHI 22390395, 15K15761).

\section{Competing Interests}

The authors have declared that no competing interest exists. 


\section{References}

1. Talge NM, Neal C, Glover V, et al. Antenatal maternal stress and long-term effects on child neurodevelopment: how and why? J Child Psychol Psychiatry. 2007;48:245-261.

2. Bustamante C, Bilbao P, Contrerans W, et al. Effects of prenatal stress and exercise on dentate granule cells maturation and spatial memory in adolescent mice. Int J Dev Neuroscience. 2010;28:605-609.

3. Lemaire V, Koehl M, Le Moal M, Abrous DN. Prenatal stress produces learning deficits associated with an inhibition of neurogenesis in the hippocampus. Proc Natl Acad Sci USA. 2000;97:11032-11037.

4. Weinstock M. The potential influence of maternal stress hormones on development and mental health of the offspring. Brain Behav Immun. 2005;19:296-308

5. Grandwald NJ, Brunton PJ. Prenatal stress programs neuroendocrine stress response and affective behaviors in second generation rats in a sex-dependent manner. Psychoneuroendocrinology. 2015; 62:204-216.

6. Koo JW, Kim Y, Rozen S, Mauer M. Enalapril accelerates remodeling of the renal interstitium after release of unilateral ureteral obstruction in rats. J Nephrol. 2003;16: 203-209.

7. Scaccianoce S, Muscolo LA, Cigliana G, et al. Evidence for a specific role of vasopressin in sustain pituitary-adrenocortical stress response in the rat. Endocrinology. 1991;128:3138-3143.

8. Heraman JP. In situ hybridization analysis of vasopressin gene transcription in the paraventricular and supraoptic nuclei of the rat: regulation by stress and glucocorticoids. J Comp Neurol. 1995;363:15-27.

9. Makino S, Smith MA, Gold PW. Increased expression of corticotropin-releasing hormone and vasopressin messenger ribonucleic acid (mRNA) in the hypothalamic paraventricular nucleus during repeated stress: association with reduction in glucocorticoid receptor mRNA levels. Endocrinology. 1995;136:3299-3309.

10. Harbuz MS, Rees RG, Eckland D, et al. Paradoxial response of hypothalamic corticotropin-releasing factor (CRF) messenger ribonucleic acid (mRNA) and CRF-41 peptide and adenohypophysial proopiomelanocortin mRNA during chronic inflammatory stress. Endocrinology. 1992;130:1394-1400.

11. Lightman SL, Harbuz MS. Expression of corticotropin releasing factor mRNA in response to stress. In: Chadwick DJ, Marsh J, Axkill K, eds. Corticotropin-Releasing Factor. Wiley, Chichester, UK;1993:173-188.

12. Gage FH. Neurogenesis in the adult brain. J Neurosci. 2002;22:612-613.

13. Lee KJ, Kim SJ, Kim SW, et al. Chronic mild stress decreases survival, but not proliferation, of new-born cells in adult rat hippocampus. Exp Mol Med. 2006;38:44-54.

14. Markakis EA, Gage FH. Adult-generated neurons in the dentate gyrus send axonal projections to field CA3 and are surrounded by synaptic vesicles. J Comp Neurol. 1999; 406:449-460.

15. Cameron HA, McKay RD. Adult neurogenesis produces a large pool of new granule cells in dentate gyrus. J Comp Neurol. 2001;435:406-417.

16. van Praag H, Schinder AF, Christie BR, et al. Functional neurogenesis in the adult hippocampus. Nature. 2002;415:1030-1034.

17. Gould E, Beylin A, Tanapat P, Reeves A, Shors TJ. Learning enhances neurogenesis in the hippocampal formation. Nat Neurosci. 1999;2:260-265.

18. Revest JM, Dupret D, Koehl M, et al. Adult hippocampal neurogenesis is involved in anxiety-related behaviors. Mol Psychiatry. 2009;14:959-967.

19. Petrik D, Lagace DC, Eisch AJ. The neurogenesis hypothesis of affective and anxiety disorders: are we mistaking the scaffolding for the building? Neuropharmacology. 2012;62: 21-34.

20. Fuchs E, Flügge G. Stress, glucocorticoids and structural plasticity of the hippocampus. Neurosci Biobehav Rev. 1998;23:295-300.

21. Kempermann G, Brandon EP, Gage FH. Environmental stimulation of $129 / \mathrm{SvJ}$ mice causes increased cell proliferation and neurogenesis in the adult dentate gyrus. Curr Biol. 1998;8:939-942.

22. Kondo H, Kurahashi M, Mori D, et al. Hippocampus-dependent spatial memory impairment due to molar tooth loss is ameliorated by an enriched environment. Arch Oral Biol. 2016;61:1-7.

23. Murray PS, Holmes PV. An overview of brain-derived neurotrophic factor and implications for excitotoxic vulnerability in the hippocampus. Int J Pept. 2011;2011: 654085

24. Ninan I. Synaptic regulation of affective behaviors; role of BDNF. Neuropharmacology. 2014; 76:684-695.

25. Castrén E, Rantamäki T. The role of BDNF and its receptors in depression and antidepressant drug action: reactivation of developmental plasticity. Dev Neurobiol. 2010;70:289-297.

26. Shimada H, Makizako H, Doi T, et al. A large cross-sectional observational study of serum BDNF, cognitive function, and mild cognitive impairment in the elderly. Front Aging Neurosci. 2014;6:69.

27. Hashimoto K, Shimizu E, Iyo M. Critical role of brain-derived neurotrophic factor in mood disorders. Brain Res Rev. 2004;45:104-114.

28. Shimizu E, Hashimoto $\mathrm{K}$, Okamura N, et al. Alterations of serum levels of brain-derived neurotorophic factor (BDNF) in depressed patients with or without antidepressants. Biol Psychiatry. 2003;54:70-75.

29. Tsankova NM, Berton O, Renthal W, et al. Sustained hippocampal chromatin regulation in a mouse model of depression and antidepressant action. Nat Neurosci. 2006;9:519-525.

30. Kubo K, Iinuma M, Chen H. Mastication as a stress-coping behavior. BioMed Res Int. 2015;2015:876409.
31. Chen $\mathrm{H}$, Iinuma $\mathrm{M}$, Onozuka $\mathrm{M}$, Kubo KY. Chewing Maintains Hippocampus-Dependent Cognitive Function. Int J Med Sci. 2015;12:502-509.

32. Azuma K, Zhou Q, Niwa M, Kubo KY. Association between Mastication, the Hippocampus, and the HPA Axis: A Comprehensive Review. Int J Mol Sci. 2017;18: E1687.

33. Tanaka T, Yoshida M, Yokoo H, Tomita M, Tanaka M. Expression of aggression attenuates both stress-induced gastric ulcer formation and increases in noradrenaline release in the rat amygdala assessed by intracerebral microdialysis. Pharmacol Biochem Behav. 1998;59:27-31.

34. Furuzawa M, Chen H, Fujiwara S, Yamada K, Kubo K. Chewing ameliorates chronic mild stress-induced bone loss in senescence-accelerated mouse (SAMP8), a murine model of senile osteoporosis. Exp Gerontol. 2014;55:12-18.

35. Azuma K, Furuzawa M, Fujiwara S, et al. Effects of Active Mastication on Chronic Stress-Induced Bone Loss in Mice. Int J Med Sci. 2015;12:952-957.

36. Miyake S, Yoshikawa G, Yamada K, et al. Chewing ameliorates stress-induced suppression of spatial memory by increasing glucocorticoid receptor expression in the hippocampus. Brain Res. 2012;1446:34-39.

37. Kubo K, Sasaguri K, Ono Y, et al. Chewing under restraint stress inhibits the stress-induced suppression of cell birth in the dentate gyrus of aged SAMP8 mice. Neurosci Lett. 2009;466:109-113.

38. Onishi M, linuma M, Tamura Y, Kubo K. Learning deficits and suppression of the cell proliferation in the hippocampal dentate gyrus of offspring are attenuated by maternal chewing during prenatal stress. Neurosci Lett. 2014;560:77-80

39. Saitoh A, Hirose N, Yamada M, et al. Changes in Emotional behavior of mice in the hole-board test after olfactory bulbectomy. J Pharmacol Sci. 2006;102:377-386.

40. Suzuki A, linuma M, Hayashi S, et al. Maternal chewing during prenatal stress ameliorates stress-induced hypomyelination, synaptic alterations, and learning impairment in mouse offspring. Brain Res. 2016;1651:36-43.

41. Ichihashi Y, Arakawa Y, Iinuma M, et al. Occlusal disharmony attenuates glucocorticoid negative feedback in aged SAMP8 mice. Neurosci Lett. 2007;427:71-76

42. Freeman AI, Munn HL, Lyons V, et al. Glucocorticoid down-regulation of rat glucocorticoid receptor does not involve differential promoter regulation. J Endocrinol. 2004;183:365-374.

43. Franklin KBJ, Paxinos G. The mouse brain in stereotaxic coordinates. Academic Press, New York, USA; 1996:93.

44. Hsu DT, Chen FL, Takahashi LK, Kalin NH. Rapid stress-induced elevations in corticotropin-releasing hormone mRNA in rat central amygdala nucleus and hypothalamic paraventricular nucleus: an in situ hybridization analysis. Brain Res. 1998;788:305-310.

45. Takagi Y, Nozaki K, Takahashi J, et al. Proliferation of neuronal precursor cells in the dentate gyrus is accelerated after transient forebrain ischemia in mice. Brain Res. 1999; 831:283-287.

46. Cheng H, Yu J, Jiang Z, et al. Acupucture improves cognitive deficits and regulates the brain cell proliferation of SAMP8 mice. Neurosci Lett. 2008;432:111-116.

47. Ohta E, Nihira T, Uchino A, et al. I2020T mutant LRRK2 iPSC-derived neurons in the Sagamihara family exhibit increased Tau phosphorylation through the AKT/GSK-3 $\beta$ signaling pathway. Hum Mol Genet. 2015;24:4879-4900.

48. Glover V. Prenatal stress and its effects on the fetus and the child: possible underlying biological mechanisms. Adv Neurobiol. 2015;10:269-283.

49. King S, Dancaause K, Turcotte-Tremblay AM, et al. Using natural disasters to study the effects of prenatal stress on child health and development. Birth Defects Res C Embryo Today. 2012;96:273-288.

50. Brunton PJ, Russell JA. Prenatal social stress in the rat programmes neuroendocrine and behavioral responses to stress in the adult offspring: sex specific effects. J Neuroendocrinol. 2010;22:258-271.

51. Mueller BR, Bale TI. Sex-specific programming of offspring emotionality alter stress early in pregnancy. J Neurosci. 2008;28:9055-9065.

52. Wingenfield K, Wolf OT. HPA axis alterations in mental disorders: impact on memory and its relevance for therapeutic interventions. CNS Neurosci Ther. 2011;17:714-722.

53. Kapoor A, Dunn E, Kostaki A, et al. Fetal programming of hypothalamo-pituitary-adrenal function: prenatal stress and glucocorticoids. J Physiol. 2006;572:31-44

54. Miyagawa $\mathrm{K}$, Tsuji M, Ishii D, et al. Prenatal stress induces vulnerability to stress together with the disruption of central serotonin neurons in mice. Behav Brain Res. 2015;277:228-236.

55. Maccari S, Krugers HJ, Morley-Fletcher S, et al. The consequences of early-life adversity: neurobiological, behavioral and epigenetic adaptations. J Neuroendocrinol. 2014;26:707-723.

56. Henry C, Kabbai M, Simon $H$, et al. Prenatal stress increases the hypothalamo-pituitary-adrenal axis response in young and adult rats. J Neuroendocrinol. 1994;6:341-345.

57. Ma XM, Lightman SL. The arginine vasopressin and corticotrophin-releasing hormone gene transcription response to varied frequencies of repeated stress in rats. J Physiol. 1998;510:605-614.

58. Ma XM, Levy A, Lightman SL. Emergence of an isolated arginine vasopressin (AVP) response to stress after repeated restraint: a study of both AVP and Corticotropin-releasing hormone messenger ribonucleic acid (RNA) and heteronuclear RNA. Endoclinology. 1997;138:4351-4357. 
59. Lightman SL, Young WS 3rd. Corticotropin-releasing factor, vasopressin and pro-opiomelanocortin mRNA responses to stress and opiates in the rats. J Physiol. 1988; 403:511-523.

60. Hori N, Yuyama N, Tamura K. Biting suppresses stress-induced expression of corticotropin-releasing factor (CRF) in the rat hypothalamus. J Dent Res. 2004;83:124-128.

61. Sasaguri K, Kikuchi M, Hori N, et al. Suppression of stress immobilization-induced phosphorylation of ERK $1 / 2$ by biting in the rat hypothalamic paraventricular nucleus. Neurosci Lett. 2005;383:160-164.

62. Sasaguri K, Yoshikawa G, Yamada K, et al. Combination of chewing and stress up-regulates hippocampal glucocorticoid receptor in contrast to the increase of mineralocorticoid receptor under stress only. Neurosci Lett. 2012;519:20-25.

63. Dupret D, Revest JM, Koehl M, et al. Spatial relational memory requires hippocampal adult neurogenesis. PLos One. 2008;3:e1959.

64. Epp JR, Chow C, Galea LAM. Hippocampus-dependent learning influences hippocampal neurogenesis. Front Neurosci. 2013;7:57.

65. Wetmore C, Ernfors P, Persson H, Olson L. Localization of brain-derived neurotrophic factor mRNA to neurons in the brain by in situ hybridization. Exp Neurol. 1990;109:141-152.

66. Lucassen PJ, Bosch OJ, Lousma E, et al. Prenatal stress reduces postnatal neurogenesis in rats selectively bred for high, but not low, anxiety: possible key role of placental 11 beta-hydroxysteroid dehydrogenase type 2 . Eur J Neurosci. 2009;29:97-103.

67. Zuena AR, Mairesse J, Casolini P, et al. Prenatal restraint stress generates two distinct behavioral and neurochemical profiles and female rats. PLos One. 2008;3:e2170.

68. Boersma GJ, Lee RS, Corgner ZA, et al. Prenatal stress decreases Bdnf expression and increases methylation of Bdnf IV in rats. Epigenetics. 2014;9:437-447.

69. Amat J, Baratta MV, Paul E, et al. Medial prefrontal cortex determines how stressor controllability affects behavior and dorsal raphe nucleus. Nat Neurosci. 2005;8:365-371.

70. Kim JJ, Lee HJ, Han JS, Packard MG. Amygdala is critical stress-induced modulation of hippocampal long-term potentiation and learning. J Neurosci. 2001;21:5222-5228.

71. Morilak DA, Barrera G, Echevarria DJ, et al. Role of brain noradrenaline in the behavioral response to stress. Prog Neuropsychopharmacol Biol Psychiatry. 2005;29:1214-1224.

72. Séguéla P, Watkins KC, Geffard M, Descarries L. Noradrenaline axon terminals in adult rat neocortex: an immunocytochemical analysis in serial thin sections. Neuroscience. 1990;35:249-264.

73. Kang YM, Ouyang W, Chen JY, et al. Norepinephrine modulates single hypothalamic arcuate neurons via a1 and $\beta$ adrenergic receptors. Brain Res. 2000;869:146-157.

74. McCall JG, Al-Hasani R, Suida ER, et al. CRH engagement of the locus coeruleus noradrenergic system mediates stress-induced anxiety. Neuron. 2015;87:605-620.

75. Seo JH, Kuzhikandathil EV. Dopamine D3 receptor mediates preadolescent stress-induced adult psychiatric disorders. PLos One. 2015;10:e0143908.

76. Abercrombie ED, Jacobs BL. Single-unit response of noradrenergic neurons in the locus coeruleus of freely moving cats. II. Adaptation to chronically presented stressful stimuli. J Neurosci. 1987;7:2844-2848.

77. Berridge CW, Mitton E, Clark W, Roth RH. Engagement in non-escape (displacement) behavior elicits a selective and lateralized suppression of frontal cortical dopaminergic utilization in stress. Synapse. 1999;32:187-197.

78. Gómez FM, Giralt MT, Sainz B, et al. A possible attenuation of stress-induced increases in striatal dopamine metabolism by the expression of non-functional masticatory activity in the rat. Eur J Oral Sci. 1999;107:461-467.

79. Yamada K, Narimats Y, Ono Y, et al. Chewing suppresses the stress-induced increase in the number of pERK-immunoreactive cells in the periaqueductal gray. Neurosci Lett. 2015;599:43-48.

80. Martijena ID, Rodríguez Manzanares PA, Lacerra C, Molina VA. Gabaergic modulation of the stress response in frontal cortex and amygdala. Synapse. 2002;45:86-94.

81. Thomas AS, Rodrigo AE, Craig WB. Coping behavior causes asymmetric in neuronal activation in the prefrontal cortex and amygdala. Synapse. 2009;63:82-85.

82. Ono $Y$, Koizumi S, Onozuka M. Chewing prevents stress-induced hippocampal LTD formation and anxiety-related behavior: a possible role of the dopaminergic system. Biomed Res Int. 2015;2015:294068. 